\title{
ESTÉTICA Y MÍSTICA EN LA RECUPERACIÓN EXPERIENCIAL DEL SÍMBOLO ${ }^{1}$
}

\author{
José Barrientos Rastrojo
}

\begin{abstract}
Resumen: Este trabajo parte de la debilitación o pérdida del símbolo en nuestra sociedad contemporánea. Resume cómo la modernidad renunció a él asentada en discursos ilustrados. Establecidos estos fundamentos, analiza las bases para su recuperación, localizando, previamente, al símbolo respecto al signo y a la analogía. Finalmente, concluye con una propuesta restauradora del concepto por medio de la experiencia. Este último concepto se abrirá desde los mundos de la estética y mística.
\end{abstract}

Palabras Clave: Símbolo. Experiencia. Estética. Mística. Analogía.

\section{La PÉRDIDA DEL SÍMBOLO Y DE LA FUNCIÓN SIMBÓliCa EN LA SOCIEDAD CONTEMPORÁNEA}

La Ilustración firmaba con satisfacción, y ciertos resabios de alevosía, el certificado de defunción de las etapas históricas que vinculaban con la superstición y la religión. El avance a través de los tres estados de la sociedad que recoge el Curso de filosofía positiva de Auguste Comte es testigo de ello: las fases teológica y metafísica habían desembocado en la positiva (COMTE, 2003). El fetichismo, el politeísmo y el monoteísmo serán sustituidos por el método científico basado en la observación, la experimentación y el uso de la racionalidad argumental. Esta cronología epocal es repetida en el siglo XX por autores como Karl Mannheim en Ideología y utopia (MADRID, 1997) y por Gilles Lipovetsky en El crepúsculo del deber (LIPOVETSKY, 2002).

A pesar de estos cantos de sirena ilustrados, algunos teóricos de la segunda mitad del siglo pasado comenzaron a dudar de que realmente se

\footnotetext{
${ }^{1}$ Este artículo se inscribe entre las actividades del Proyecto de Investigación "Proyecto de Investigación "Ciencia, Tecnología y Sociedad: Problemas políticos y éticos de la computación en nube como nuevo paradigma socioético” (Referencia: FFI2013-46908-R).

2 Profesor adscrito al Departamento de Metafísica y Corrientes Actuales de la Filosofía, Ética y Filosofía Política, Vicedecano de Estudiantes de la Facultad de Filosofía (Universidad de Sevilla) y Director del Grupo de Investigación "Experiencialidad” (Referencia: HUM 964). Sus temas de investigación son la sabiduría, la experiencialidad (o experiencias de vida) y la Filosofía Aplicada. Ha realizado estancia de investigación en la Universidad de Harvard, la Universidad de Cambridge, la Universidad de Princeton, la Universidad de Tokio o la Universidad de Chicago, entre otras.E-mail: barrientos@us.es http://dx.doi.org/10.1590/S0101-31732017000300010
} 
hubiese dado un paso adelante, pues el proceso incluía pérdidas de elementos clave para el ser humano (como el símbolo o el mito) y defendía un tipo de racionalidad excesivamente absolutista y totalitarista. De hecho, aunque María Zambrano (1904-1991) suscribe el programa Comte como real, abomina de su optimismo, lamentándose de que nuestros ojos se encuentren, hoy, "[...] desnudos de mitología, ávidos de visión, visionarios en ayunas en pleno eclipse." (ZAMBRANO, 2004, p. 79).

Para la modernidad, la desafección religiosa y el extravío del rito y el mito redimía a la persona de un pasado lleno de falsedad porque, sostenía, "[...] lo que no responde a la razón es mito, engańo adormecedor; sombra de una sombra moviéndose sin despejarse de la pétrea parada de la caverna" (ZAMBRANO, inédito a, p. 10), llegando a afirmar que "[...] la poesía no es sólo error, es una mentira inventada creada voluntariamente." (ZAMBRANO, inédito b, p. 4). Sin embargo, Zambrano subraya que la impronta positivista provocaba una ceguera a ciertos tipos de realidades: el método científico había despejado sombras y había atraído avances tecnológicos, pero su imperialismo también incapacitó a la sociedad para aprehender las entidades que no gozasen de la claridad y distinción cartesiana mediadas por la óptica del físico o del matemático.

Martin Heidegger, filósofo alemán que desarrolló su labor en el siglo XX, profundiza en la pérdida aludida por Zambrano con el siguiente argumento. El conocimiento positivista de los entes se opera dentro de ciertos marcos fijados por el pragmatismo y sólo da derecho a existir a aquellos entes que pasan por ese filtro. Por ejemplo, el marco pragmatista decía que un zapato sólo podía existir como tal si respondía a una función determinada; cuando abandonaba esta función su legitimidad existencial desaparecía.

Las botas campesinas las lleva la labradora cuando trabaja en el campo y sólo en ese momento son precisamente lo que son. Lo son tanto más cuanto menos piensa la labradora en sus botas durante su trabajo, cuando ni siquiera las mira ni las siente. (HEIDEGGER, 2001, p. 23).

Las botas de una campesina difuminan su existencia cuando dejan de responder a su objetivo pragmatista. El fenómeno sería análogo a cuando se reduce un árbol a "elemento decorativo", a "instrumento para limitar los efectos de la contaminación" o a "la materia prima para construir una silla o una mesa”. Con este juego, ¿no se silencia la voz de autodeterminación del 
árbol desde sí mismo para imponerle un significado que responde a intereses pragmáticos de quien lo contempla? La modernidad y la Ilustración han hurtado a la realidad, a los objetos y a los entes en general la posibilidad de defender los sentidos que le son propios y no impuestos por otros.

La estética y la religión han recibido los más duros golpes en esta lógica: las hermenéuticas pragmatistas impuestas exigen interpretaciones que no se corresponden con lo que son realmente sus objetos. Cuando se acota una pintura dentro de "objeto para curar" por medio de una arteterapia o una religión dentro de una entidad que sirve para dominar (o adormecer) a los pueblos o calmar el vértigo a lo desconocido (MARX, 2005, p. 50; FREUD, 1981, p. 2969, 2976-2977), se desatienden los significados auténticos que surgen desde la entraña de esas entidades para imponerles unos pragmatistas que les son foráneos. He aquí la clave del extravío simbólico.

La práctica ritual del dominico y filósofo Mauricio Beuchot (nacido en 1950) constituye el punto de partida para su comprensión de las perspectivas zambraniana y heideggeriana. Así, concluye que no sólo hemos perdido a los dioses sino a los símbolos: los primeros "[...] han enmudecido" (BEUCHOT, 2011, p. 49) puesto que hablaban en símbolos y no con discursos argumentales. La secularización de la sociedad, señala, ha generado grandes masas que desconocen el sentido o significado al que se dirige la vida y "[...] que obedecen a fuerzas ciegas e inconsistentes." (BEUCHOT, 2007, p. 54). El significado pragmático no apela a profundidad que cale sino a función material que no permite alcanzar trascendencia alguna. El símbolo trasladaba a un mudo configurado de acuerdo con explicaciones de los entes y fines que partían del mundo mismo y no de los impuestos por el sujeto (BEUCHOT, 1999b, p. 67).

En los marcos simbólicos, una boda se construye como un evento social con tintes cosméticos cuyo su significado se resuelve en una superficialidad sin trascendentalidad (es decir, dentro de un escenario con tintes pragmatistas). Allí, un enlace matrimonial se explica desde sí mismo: desde lo que su esencia amorosa descubre. Conecta desde la base a los contrayentes a tres niveles: entre ellos, con la comunidad y a todos con el marco trascendental (religioso o no). Ese marco trascendental conformaba la guía existencial para todos, es decir, determinaba roles sociales, aspiraciones, senderos nuevos por los que se conducían los esposos y una nueva imagen ante los demás. 
Si la sociedad contemporánea es incapaz de captar estos significados debido al absolutismo pragmatista, estamos abocados, de acuerdo con Beuchot, al "nihilismo" (BEUCHOT, 1999a, p. 202) a la pérdida de los sentidos básicos sobre los que se construye una comunidad, a la confusión de los destinos vitales y al derrumbe en la nada. También es posible el derrumbe en torno a los significados pragmatistas impuestos desde afuera pero eso es silenciar a la realidad. Por todo ello, el nihilismo citado por este autor provoca severos cambios en los planos epistemológicos, metafísicos y psicológicos.

Desde el plexo cognoscitivo, se fomenta la incomprensión de los actos simbólicos. Así, la boda pierde su potencial de acto metafísico y torna en acto aburrido y de exigido cumplimiento social.

Desde la cara metafísica, Cassirer explica que, sin el símbolo, la persona “[...] se encontraría confinada dentro de los límites de sus necesidades biológicas y de sus intereses prácticos; sin acceso al mundo ideal que se le abre, desde lados diferentes." (CASSIRER, 1967, p. 40). Esta intuición concuerda con lo que, años después, indicará Verónica Volkow para incidir en una existencia carente del símbolo: "[...] la vida del hombre sería, la de los prisioneros en la caverna de Platón [...]. Vivirá como ciego y sordo respecto a la riqueza que encierra en sí mismo; vivirá sin su lenguaje espiritual. Será un mucho y analfabeto ente atenazado, completamente perdido en el sótano de la peor de las inconsciencia." (VOLKOW apud BEUCHOT ,1999a, p. 6).

Asimismo, se derivarían psicopatologías debido a, según asevera Lacan, la dureza del día a día de aquel que no puede trascender más allá de lo físico (BEUCHOT, 2004, p. 68): se necesita narrar, imaginar, crear, saltar el muro de lo posible y de lo visible por los sentidos contiguos a un realismo romo. Pues, como añade Panikkar, sin esa fuente originaria y palpitante que encontramos en el símbolo, nuestras vidas se tornan "[...] pobres, tristes y mediocres. Para dominar esta miseria recurrimos a una multitud de cosas que la edulcoren [...] y nos identificamos con esa multitud de cosas." (PANIKKAR, 1998, p. 45).

En suma, la partida del símbolo en nuestra sociedad urge ofrecer vías para su restablecimiento. Una vez hemos pasado del optimismo positivista a la inquietud contemporánea, es hora de alcanzar una madurez que se sobreponga a ambos dislates emocionales mediante una pausada reflexión práctica sobre los fundamentos de tal rescate. 


\section{Naturaleza de la Restauración}

\subsection{EL SIGNO Y LA ALEGORÍA, REFERENCIAS INDIRECTAS ENTRE SIGNIFICANTE Y SIGNIFICADO}

Bajo la designación "símbolo" se han resguardado entidades ajenas a lo que aquí tratamos. Por ello, es preciso delimitar el sentido de nuestro ente antes de continuar. Tal tarea desvelará el universo propio de nuestro objeto de estudio.

Norbert Elías identifica el símbolo con el signo. Los símbolos coincidirían con las palabras o "pautas sonoras" (ELIAS, 1994, p. 93) que sirven para trasmitir contenidos o para referirse a objetos físicos sin que éstos estén presentes. La "casa" es el símbolo que apunta al lugar en el que un conjunto de personas con un cierto tipo de relación y función comparten una existencia. Las pautas sonoras son "regularizadas socialmente", es decir, dependen de la creación y aceptación social (ELIAS, 1994, p. 107) y poseen funciones comunitarias como la creación de agrupaciones de hablantes, la transmisión de situaciones pasadas o futuras o la apelación a objetos no presentes (ELIAS, 1994, p. 147).

Estos signos, o símbolos tanto para Elías como para Beuchot, no mantienen la relación esencial entre significante y significado descrita para los símbolos; he aquí una diferencia entre ambos: "[...] el signo es pura referencialidad a algo, y el símbolo es puro estar en lugar de algo." (BEUCHOT, 2012a, p. 27). Consecuentemente, los símbolos de Elías coinciden con los "signos arbitrarios" de Gilbert Durand (DURAND, 1968, p. 12). Durand amplía el elenco de estos últimos desde la palabra a otros de naturaleza gráfica como la calavera con las dos tibias. Estos últimos poseen una ventaja sobre la explicación realizada por las palabras: "Es más rápido dibujar sobre una etiqueta una calavera estilizada y dos tibias cruzadas que explicitar el complicado proceso por el cual el cianuro de potasio destruye la vida." (DURAND, 1968, p. 10).

Entre el signo y el símbolo, encontramos la alegoría. Su conexión con la realidad no es tan indirecta y/o arbitraria como en los signos sino que existen indicios que conectan la referencia y el referente. Así, para Todorov, la alegoría llama directamente a lo intelectivo sin necesidad de explicar cuál ha de ser la relación entre significado y significante (TODOROV 1977, p. 282). Pongamos un ejemplo de Durand: "[...] la idea de justicia se representa mediante un 
personaje que castiga o absuelve [...]. Los signos alegóricos contienen siempre un elemento concreto o ejemplar del significado." (DURAND, 1968, p. 12). Verdad y método de Gadamer asevera que "Símbolo es la coincidencia de lo sensible y lo insensible, alegoría es una referencia significativa de lo sensible a lo insensible." (GADAMER 1977, p. 51). Con ello, se incentiva desde otro polo la misma asunción: el símbolo trasluce lo trascendental en lo particular.

Con todo esto, podemos superar la crítica de ciertos autores hacia el símbolo. Éstos fundan sus afirmaciones en la arbitrariedad o convencionalidad que existe entre significante y significado en el signo, es decir, atribuyen al símbolo cualificación sígnica. Asumen que no existe una relación esencial (u ontológica) entre el significado y el significante, por lo que la referencia se construye por medio de una subjetividad (más o menos voluble) o de una ideología que persigue fines específicos. Así, el agnóstico simbólico no percibirá cómo la bandera conecta desde su entraña con el amor a la nación sino como una construcción que legitiman el poder constituido, pudiendo modificarlo el legislador si sus intereses lo demandan, ni en el rito de graduación intuirá la emanación ontológica que ahí se da, a saber, el cambio de condición básica de los graduados que impregna su rol social y su condición como ser humano.

Si el problema de la sociedad contemporánea reside en la degradación sígnica del símbolo, el objetivo de nuestro trabajo consistirá en estudiar su recuperación ontológica o esencial, que es la que verdaderamente le corresponde a nuestro objeto de estudio. Comprender esta naturaleza delineará la actuación requerida para el rescate.

\subsection{La NATURALEZA ONTOLóGica DEL SÍMBOLO}

\subsubsection{EL NEXO ONTOLÓGICO DEL SÍMBOLO}

"El símbolo no es convención ni arbitrariedad sino plasmación sensible de una realidad inteligible" (ANTÓN PACHECO, 2010, p. 373), sus dos instancias constituyentes se alean desde la raíz. Como señala El ser y el símbolo, "El símbolo no es sólo la referencia a otra cosa - lo simbolizado- sino que es esa cosa misma de alguna manera." (ANTÓN PACHECO, 2010, p. 85). El mundo religioso, consciente de esta propiedad secunda que sus ritos (simbólicos) son el acto mismo de la presencia de una trascendencia y no lo apuntan o lo representan. Durante el acto litúrgico católico, Jesucristo se hace 
presente en la hostia consagrada y no sólo lo representa. Gadamer lo explica en los contextos religiosos y estéticos en los siguientes términos:

El símbolo no es una mera señalización o fundación arbitraria de signos, sino que presupone un nexo metafísico de lo visible con lo invisible. El que la contemplación visible y el significado invisible no puedan separarse uno de otro, esta "coincidencia» de las dos esferas, es algo que subyace a todas las formas del culto religioso. Y esto mismo hace cercano el giro hacia lo estético. (GADAMER, 1999, p. 50).

Beuchot recuerda que esta transustanciación se hunde en tiempos primitivos:

Cuando [el hombre primitivo] llega a su casa o cueva [...] encontramos las pinturas y representaciones de esos animales que persigue, de los que se alimenta. Son sus iconos (o símbolos). Y al contemplarlos siente la presencia de otro modo. Les hace ritos, los invoca, los conjura. Están y no están, son y no son. (BEUCHOT, 2012b, p. 37).

Esos símbolos se entienden no en la medida en que se produzca una comprensión intelectiva de tipo sígnica o alegórica sino en tanto el contemplador se introduzca en ellos desde sus cualidades simbólicas. El símbolo se convierte en epifanía de una entraña y de una trascendencia, "epifanía de un misterio" (DURAND, 1968, p. 15). Esta epifanía es materialización de una realidad totalizante y totalizadora.

La comprensión provoca cambios en el contemplador, pues exige a la persona introducirse en un cosmos nuevo, el del símbolo, el cual le proporciona un sentido a cada una de sus acciones y sentimiento y un destino. Por eso, Todorov seńala que el símbolo es "activo y viviente" (TODOROV, 1977, p. 289). Al fin y al cabo, el contemplador acaba participando de un misterio y puede convertirse en símbolo; análogamente, los contrayentes de una boda, testigos del misterio del amor, mutan en ministros de éste último delante de la comunidad.

Las densidades misteriosas y trascendentales del símbolo explican por qué el intento de usar metodologías humanas (limitadas por un espacio y un tiempo) es ineficaz para capturar su sentido. De hecho, las visiones racionalistas-humanas generan imágenes deformadas, esto es, no acordes con la auténtica entrańa de nuestro objeto. Una pregunta puede ser respondida 
argumentalmente, pero el misterio no puede ser descifrado sino sólo contemplado. La reflexión que exige para comprenderlo requiere escucha atenta, paciencia y esperanza en que se abra. Esta comprensión simbólica demanda al sujeto dejarse absorber por su esencia; como señala Panikkar, el símbolo "[...] es tal porque simboliza y no porque es interpretado en un contenido [...] objetivo." (PANIKKAR, 1991, p. 36). Mircea Eliade se une a esta perspectiva al avisar que "traduzir uma imagem [simbólica] numa terminologia concreta, reduzindo-a a um só dos seus planos de referência é pior que mutilá-la: é aniquilá-la, anulá-la como instrumento de conhecimento." (DURAND, 1968, p. 16). La conceptualización del símbolo quiebra su capacidad activa. Expliquémoslo con un ejemplo: para el turista, aquel que hace de la realidad un compendio de objetos que integrar en su listado de elementos visitados, cualquier iglesia se alza como escaparate que cumple una función específica (la propia satisfacción del visitante) y pierde su potencia como objeto de culto, como el lugar de contemplación ritual que transforma y guía la existencia del creyente y como punto de unión entre lo mundano y lo transcendente. El turista paseará por la Meca, la Catedral de San Pedro en Roma, la Basílica de Guadalupe de México DF o la Catedral de Sava en Belgrado o por las Rosas de Sarajevo, pero no alcanzará una cabal comprensión de tales lugares porque su sacudida es a lo sumo estética y fugaz; ahora bien, no experimentará un vuelco en su corazón cuando pise una de las rosas de Sarajevo y sepa que bajo ella una vez hubo sangre de una persona bombardeada en la guerra, ni se convertirá o caerá de rodillas en el proscenio de la Basílica de Guadalupe. Rescatar el símbolo es comprenderlo en estas dimensiones íntimas porque implica conectar con su genuina naturaleza, que queda lejos de un esteticismo cosmético, es decir, sin valor ontológico.

Siguiendo este sendero, Jung diferenciaba entre la analogía y el símbolo subrayando que la primera (propia del turista) explica la idea por medio de otra idea, mientras que por medio del segundo (el creyente) aparece la idea misma (DURAND, 1968, p. 13). Ítem más: Todorov rescataba a Schelling para quien "[...] el símbolo no sólo significa sino que también es" (TODOROV, 1977, p. 292), pues "María Magdalena no sólo significa el arrepentimiento, es el arrepentimiento viviente." (TODOROV, 1977, p. 242).

La actividad social del símbolo se percibe en la creación de entes a diversos niveles. El más visible es la celebración de ritos (Semana Santa, 
Ramadán, un acto de graduación universitaria, un bautizo); por otro lado, tenemos el establecimiento de tiempos simbólicos (el día de las Fuerzas Armadas, el día del Orgullo Gay, el día del apellido de la familia en Belgrado) y, por último, la configuración de espacios simbólicos (templos, monumentos, espacios en que sucedieron acontecimientos luctuosos como las citadas rosas de Sarajevo). Estos ingredientes simbólicos configuran gran parte de la fisonomía de una región y de sus gentes; además, las distingue de otras, la distancia entre una sociedad islámica y una ortodoxa católica o de una capitalista y una comunista no depende del color de piel de sus habitantes sino de los destinos y roles dependientes de los símbolos en los que respiran. El rostro de sus actos, de sus emociones (los miedos, los atractores) y de sus modalidades de pensamientos (analítica, narrativa, religiosa, supersticiosa, estética) descansa sobre la red de símbolos compartidos, tesis central del ser simbólico de Cassirer (CASSIRER, 1971, p. 13-60). El símbolo no sólo da que pensar, como seńalaba Ricoeur (RICOEUR, 2004, p. 481-482), sino que da para vivir, da la vida de la sociedad. Por ello, el extravío simbólico nos roba nuestra existencia propiamente humana.

\subsubsection{TrascendenCia Del SÍMbolo}

Agustín de Hipona, en De la dialéctica, aludía a las capacidades trascendentales del símbolo: "[...] es algo que nos hace pensar más allá de la impresión que la cosa misma produce en nuestros sentidos." (AGUSTÍN DE HIPONA, De la dialéctica, II, I, 1). Antón Pacheco reflexiona sobre esta idiosincrasia por medio del concepto de "transitividad", que conecta a los objetos dentro de universos específicos. Lo vemos con uno de sus ejemplos:

La piedra instaura ámbitos de sentidos. De ahí que la transitividad del símbolo piedra se ponga en funcionamiento estableciendo una cadena en la que la piedra genera el símbolo casa como lugar habitacional y religador [...]. El sentido simbólico de la casa es extrapolable a otros ámbitos simbólicos adyacentes, y tenemos, así, que a la piedra y a la casa se le añaden los símbolos, entre otros, del templo y la ciudad [...]. El templo o la ciudad son fundamentos espirituales de la realidad y, por ello mismo, ejes o centros esenciales, puntos religadores de la Tierra con el Cielo, de lo sensible con lo inteligible, formas de enlace y sostenimiento de la comunicación entre el mundo inferior y el superior. Dentro de este orden de cosas, se comprende cómo de una piedra Jacob posibilitó la comunicación de Betel -la casa de Dios- y cómo esa misma piedra sirvió de fundamento al templo de Salomón; se comprende cómo una piedra puede ser la Caaba, el centro y 
fundamento del mundo; o como una ciudad, Jerusalén, se convierte en un complejo simbólico que abarca todos estos significados [...]. Jerusalén tiene su correspondencia con la Jerusalén celeste como la piedra fundamental tiene su correspondencia con la piedra angular [...]. La piedra adquiere en el hombre el significado de piedra filosofal, de templo del Espíritu Santo y, en virtud de todo este simbolismo axial, en el hombre, la piedra confluye en el símbolo del corazón como centro espiritual del ser humano. Es decir, la transitividad simbólica de la piedra nos ha llevado hasta el símbolo del corazón. Por tanto, la secuencia simbólica piedra-casa-templo-ciudad sufre una intersección por la que se incluye en la secuencia misma el simbolismo del corazón y del hombre como templo del Espíritu Santo, arrastrando estos dos últimos símbolos otro complejo simbólico que a su vez se incluirá en la secuencia precedente. (ANTÓN PACHECO, 2010, p. 230-231).

Antón Pacheco prefigura la cima última del símbolo: lo infinito (TODOROV, 1977, p. 229). Esta apertura máxima diferencia, en la óptica de Todorov, nuestro objeto de estudio de la alegoría: el sentido de ésta es finita y el del primero "infinito e inagotable" (TODOROV, 1977, p. 288); es más el símbolo manifiesta proclividad a eliminar el sentido particular (TODOROV, 1977, p. 117). Cassirer añadirá que en "[...] cada imagen mítica o artística, aparece un contenido espiritual que en sí y por sí lleva más allá de lo sensible.” (CASSIRER, 1971, p. 51).

Aclarada la naturaleza (ontológico-trascendental) del símbolo, corremos el riesgo de haberlo situado en un punto en el que no sea posible continuar con nuestra investigación: recordemos pretendíamos establecer cauces para que nuestra sociedad pueda recuperar, o comprender adecuadamente, el símbolo. Ahora bien, si éste se hospeda en un talante que excede a la limitación espacio-temporal de individuos y comunidades, ¿no superaría también sus capacidades de comprensión? Así es si asumimos una comprensión objetiva inherente, por ejemplo, al método científico modernista, puesto que éste sólo alcanzaría objetos integrables en la visión del ser humano. En ese caso, ¿̨no será la hermenéutica simbólica una tarea de dioses, aquellos que exceden o están fuera del espacio y del tiempo?, ¿no tendrán razón aquellos que, en la modernidad, no supieron aprehender a nuestra entidad (o lo hicieron de modo objetivista y reduccionista) y que apuntaron como ingenuidad a aquellos hombres primitivos que creyeron capturar su sentido más allá de los esquemas de la metodología positivista? 


\section{MODELOS PARA UNA RESTAURACIÓN-COMPRENSIÓN DEL SÍMBOLO EN LA SOCIEDAD CONTEMPORÁNEA}

\subsection{El MODELO DE LA MÍSTICA}

La propuesta ricoeuriana para recuperar-comprender el símbolo nos parece acertada y consistente con la propiedad ontológica del símbolo, es decir, con esa capacidad inherente de unir (o hacer transparente) lo universal o trascendental en lo particular: "[...] lo que necesitamos es una interpretación que respete el enigma originario de los símbolos, que deje que éstos la instruyan, pero que, a partir de ahí, promuevan el sentido." (RICOEUR, 2004, p. 483). Décadas antes, María Zambrano había avisado que no se debe obligar a la palabra originaria a emerger, puesto que aparecería con una indumentaria que ocultaría su auténtica piel; por el contrario, la comprensión de la palabra originaria y del símbolo exige respetar los modos en que deseen desvelarse. Ahora bien, si no podemos obligar a estas realidades a abrirse a nuestro campo de visión, ¿qué solución nos queda? La solución viene con un cambio de perspectivas: hemos de ser nosotros los que nos movamos a su legitimidad en lugar de atraerlas al nuestro

Cuando el ciudadano ciego describe el símbolo como construcciones ideológicas generadas arbitrariamente (es decir, le niega su conexión con fondos de realidad) o interesadas (construidas por sujetos que buscan objetivos específicos), se encuentra en su derecho igual que el daltónico tiene derecho a engañarse imponiendo su cromatismo erróneo al sano. Este ciudadano puede alegar postmodernamente que cada individuo posee legitimidad para defender la propia perspectiva, equiparándolas a todas. Sin embargo, no comprende que la visión del creyente no le pertenece a él como una entre decenas sino que él pertenece a esa visión: él no crea la visión sino que la recibe. Por eso, la perspectiva de quien comprende el símbolo es más valiosa porque no la ha creado por sí mismo, sino que la ha recibido desde aquel que tiene máxima legitimidad para generarla: el propio símbolo.

La mística se ha ocupado de entidades tan amplias como el símbolo: Dios. Su comprensión corre por los cauces que aquí signamos: dejar que él nos ofrezca el medio para que lo entendamos. Panikkar apela al "genitivo subjetivo" (PANIKKAR, 1999, p. 170): la experiencia de otro dentro (genitivo) de mí (subjetivo). No se busca "[...] mi experiencia sobre Dios, sino la experiencia de Dios -en mí y a través de mí-” (PANIKKAR, 1999, p. 78), ésta “[...] no 
consiste en buscar sino en hacerse el encontradizo" (PANIKKAR, 1999, p. 78-79), introducirse en el círculo de esa experiencia para comprender a Dios, desde dentro, respirando su atmósfera, privilegiando su ser sobre el nuestro, dejando que el sonido de su eco haga resonar cuerdas de nuestro propio interior como sucede en la base de la teoría de Huainanzi:

Cuando el afinador del laúd tañe la cuerda gong [de un instrumento], la misma cuerda [en otro instumento] responde por resonancia; y cuando pinza la cuerda jiao [de un instrumento] de pone a vibrar. Es el fenómeno de la armonía mutua entre notas similares. (HUAINANZI apud CHENG, 2002, p. 261).

De alguna forma, "[...] es un caminar con Dios [...] siendo Dios" (PANIKKAR, 1999, p. 109), idea que ya explicitaba Platón en su consideración del poeta como alguien que portaba a Dios, como un "entusiasmado", un "entheos", y que es retomada en la mística medieval, siendo secularizada esta idea por Bruno por medio del concepto "furor heroico" (UBALDO 1999, p. 108).

Dentro de la esfera simbólica, las sociedades adquieren nuevos filtros (y capacidades cognoscitivas más amplias) por los que entienden realidades de las que no se apercibían debido a su limitación espacio temporal; individualmente conseguimos "[...] reconocernos en él como nosotros mismos, vivimos en él, con él y de él." (PANIKKAR, 1999, p. 102). Sólo cuando se ama a una persona se entienden las propias capacidades donativas; es preciso adquirir la libertad después de años de prisión para vislumbrar la necesidad existencial de permanecer libre de ataduras. En el plano religioso, la hermenéutica vital se abre hasta límites insospechados porque cada instancia real adquiere un significado: "[...] si Dios es todas las cosas, estas cosas adquieren su plena validez.” (PANIKKAR, 1999, p. 103). Trasladémoslo al universo simbólico, quien ha recibido la cruz al mérito profesional, se apercibe de modo profundo del sentido del esfuerzo realizado a cada instante y de las recompensas de la labor bien realizada.

De esta forma, la comprensión (hermenéutica) auténtica es más que la intelección de un suceso: consiste en la materialización de una entidad previamente oculta y no presente. En términos de Antón Pacheco: "La hermenéutica es algo más que una técnica interpretativa: la hermenéutica es un recorrido espiritual [...]. Causa una transformación radical en el mundo sensible, el cual queda convertido en un ámbito de luz y transparencia” (ANTÓN PAcheco, 2010, p. 94), "[...] es el camino que nos conduce desde 
lo presente hasta la presencia, desde lo modelado hasta el modelo, desde la letra hasta el espíritu." (ANTÓN PACHECO, 2010, p. 206).

\subsection{El MOdelo estético}

El modelo místico concierta con la visión del artista, citado por Heidegger más arriba, cuando pintaba las botas. No pretende dar una óptica subjetivista del calzado de la campesina sino dejar que éste se manifieste a través de las manos del artista, que pasa a un segundo plano. En la misma línea, Beuchot defenderá que "[...] el poeta capta la vida oculta en las cosas inertes, el corazón de la naturaleza, el alma del mundo" (BEUCHOT, 2013, p. 53) respetando sus propios modos de darse.

John Dewey proporciona una perspectiva del fenómeno desde una aproximación diferente: la experiencia artística. La experiencia del contemplador de ciertas obras artísticas se han separado de la vivencia directa y originaria que les dio el ser, tal como sucede en los turistas. Esta circunstancia rompe el acto estético (DEWEY, 2008, p. 3), puesto que éste se logra “[...] cuando la obra llega a ser la experiencia de un ser humano" (DEWEY, 2008, p. 4), cuando inspira: "Inspirarse es inflamarse con un pensamiento o escena. Lo que se inflama debe también arder por sí mismo hasta convertirse en cenizas, o expresarse en un material que transforma el material crudo en un producto refinado." (DEWEY, 2008, p. 75).

La comprensión simbólica se inscribe en este espíritu artístico: el contemplador ha de mantenerse como ser inspirado delante del símbolo, es decir, no será alguien incardinado en un espíritu agostado y cegado; así, el símbolo “[...] impulsará todo su ser." (DEWEY, 2008, p. 67). De hecho, la comprensión permite la fusión con el símbolo, y con la obra artística, o la disolución del sujeto en ese objeto. Según María Zambrano, el poeta se emborracha de realidad (ZAMBRANO, 2001, p. 33-34) y pierde su propia autonomía al sumergirse en una totalidad que lo utiliza como medio para fines propios (ZAMBRANO, 1993, p. 70; ZAMBRANO, 2001, p. 25, 28, 41). De acuerdo con Cassirer, "[...] en la contemplación de una gran obra de arte no sentimos una separación entre el mundo subjetivo y el objetivo; no vivimos en la realidad plena y habitual de las cosas físicas ni tampoco vivimos, por completo, en una esfera individual. Más allá de [la distinción de] estas dos esferas detectamos un nuevo reino, el de las formas plásticas, musicales o poéticas." (CASSIRER, 1967, p. 126). 
De las concomitancias entre arte y símbolo, se infieren consecuencias comunes, por ejemplo, el arte "[...] el arte significa la evasión de este mundo convencional hueco y estrecho; nos conduce de nuevo $a$ las fuentes verdaderas de la realidad" (CASSIRER, 1967, p. 139), tal como indicamos más arriba para el símbolo.

\subsection{La experiencia como campo común}

Tanto el esqueleto místico como el artístico forjan esquemas de recuperación que siguen los pasos del rescate del símbolo. La instancia común de ambos es la "experiencia", esto es, la vivencia directa, vívida y transformadora resultante del contacto y/o disolución en un ente trascendental divino o artístico. Sólo quien experimenta a Dios o El beso de Klimt los comprende y escapa de la condición de turista, pues se transforman al fusionarse con realidades que le son ajenas.

Beuchot, Panikkar, Zubiri y Dilthey, en la tradición occidental, y Nishida, en la tradición oriental, han descrito la experiencia como un contacto directo con la realidad, sin mediaciones. Beuchot recalca que "[...] la experiencia, el sentir, es descifrar símbolos, pero de manera inmediata" (BEUCHOT, 2012b, p. 81), Panikkar la trata como el "[...] toque que tenemos con la realidad" (PANIKKAR, 1999: 17), Zubiri como el "[...] comercio efectivo con las cosas" (ZUBIRI, 1940, p. 189) y Nishida como "[...] conocer los hechos tales como ellos son, conocer de conformidad con hechos renunciando por completo a las propias elaboraciones." (NISHIDA, 1995, p. 41). Para Dilthey, que equipara nuestro concepto con la "Erlebnis", en la experiencia se encuentra "[...] lo que está dado de manera inmediata" (GADAMER 1977, p. 45); Gadamer, fuertemente influenciado por Dilthey lo explica en los siguientes términos:

Erleben significa para empezar «estar todavía en vida cuando tiene lugar algo». A partir de aquí la palabra Erleben adquiere un matiz de comprensión inmediata de algo real, en oposición a aquello de lo que se cree saber algo, pero a lo que le falta es garantía de una vivencia propia, bien por haberlo tomado de otros, o por haberlo simplemente oído, bien por ser inferido, supuesto o imaginado. Lo vivido (das Erlebte) es siempre lo vivido por uno mismo. (GADAMER, 1977, p. 44). 
La experiencia, de acuerdo con Pannikar, implica "[...] tocar con mi ser la totalidad del Ser." (PANIKKAR, 1999, p. 19). Dewey añade desde el campo de la estética que la experiencia supone una "vitalidad elevada" (DEWEY, 2008, p. 21); nosotros añadiríamos, con fines explicativos, que ese ascenso es deudor de una apertura del sujeto a contextos más amplios, a ser más sí mismo, a acrecentarse a sí mismo por medio de aquello en lo que se disuelve el sujeto o la sociedad. Cuando se contempla, por vez primera, con ojos experienciales El Guernica de Picasso o los edificios bombardeados por la OTAN de la calle Nemanjina en Belgrado la sorpresa es síntoma de una amplitud existencial (sea dolorosa, gratificante o de otra índole) que recibe el espíritu al contacto con una verdad que es más amplia que cualquier individuo. El espacio y el tiempo de la persona no están preparados para el contacto directo con esos restos abominables en que palpita el horror del pasado. La explicación (objetiva, fría y con intención de ofrecer un dato cultural de primer nivel) de la guía turística no es comparable a la impresión experiencial obtenida, si se alcanza. La primera es esperable, es decir, se ubica dentro de cánones objetivos y la objetividad es manejable; las palabras de la guía son ciencia, pero la "[...] experiencia no es ciencia, no es episteme, no pertenece a la epistemología sino que, antes bien, la funda." (PANIKKAR, 1999, p. 17). La comprensión intelectiva u objetiva toca la realidad en el nivel cognoscitivo, pero, con la experiencia, la toco desde la citada "totalidad de mi ser". Por todo ello, no erraba Zubiri cuando advertía que sólo mediante la experiencia, "[...] las cosas ponen su realidad en manos del hombre.” (ZUBIRI, 1940, p. 190). El conocimiento intelectivo pone en las manos del espectador una perspectiva desde la que se otea una realidad, pero la experiencia carece de perspectivas, o las posee todas, al vincular al sujeto directamente con lo real.

Esta interpretación se equipara al cumplimiento, repetición y actualización de lo dado (ANTÓN PACHECO, 2010, p. 189): conocer es actualizar una realidad, por eso, quien mejor entiende el amor es el amante y para entender una novela hay que convertirse en autor o alcanzar la experiencia a la que éste dio lugar como señalaba Scheleiermacher para llegar a comprender "[...] mejor de lo que él mismo podría dar cuenta de sí mismo." (SCHLEIERMACHER, 1999, p. 81).

¿Cómo es posible ver estando ajeno a punto de visto alguno? Porque la fusión del sujeto o de la sociedad con la experiencia provoca que retroceda antes de la separación se sujeto y objeto. La experiencia se aprehende desde una instancia que es previa al sujeto, aquel que posee una determinación 
espacio-temporales particular. Esto es debido a que la experiencia consiste en una unidad que se capta de forma total. Dewey lo explica en los siguientes términos:

Una experiencia tiene una unidad que le da su nombre, esa comida, esa tempestad, esa ruptura de la amistad [...] está constituida por una cualidad determinada que impregna la experiencia entera [...]. Esta unidad no es ni emocional, ni práctica, ni intelectual, porque estos términos denominan distinciones que la reflexión puede hacer dentro de ella. (DEWEY, 2008, p. 43).

Así, la categoría "experiencia", donde se encuadra la experiencia simbólica, pertenece a la metafísica antes que a la física. Su aprehensión depende de un acto filosófico antes que de uno psicológico: el sujeto se percata de rostros particulares de un rito o un símbolo, pero sólo la participación experiencial en la totalidad del acto simbólico lo capacita para la comprensión.

\section{CONCLUSIÓN. La EXPERIENCIA COMO MEDIO DE RESTAURACIÓN SIMBÓliCa EN NUESTRA SOCIEDAD}

\subsection{SER EXPERIMENTADOS POR LO OTRO EN LUGAR DE EXPERIMENTAR LO OTRO}

No todas las vivencias son experiencias; sólo lo serán aquellas que provocan una quiebra metamórfica en nuestro ser y catalizan el ec-stasío (estar fuera de nosotros mismos) para situar en nuestro centro un ser no personal. Un evento simbólico se percibirá como vivencia o como experiencia según el centro sea un yo que intenta controlar o uno que se deja dominar por el símbolo. En el segundo caso, la persona (o el grupo) asume la interpretación como un acto que consiste en "[...] cumplir, repetir y actualizar el símbolo interpretado.” (ANTÓN PACHECO, 2010, p. 189).

Visto lo anterior, "[...] el contenido interiorizado presenta algunas semejanzas u homologación con aquel que intenta asumirlo.” (ANTÓN PACHECO, 2010, p. 83). Ítem más, Arte y símbolo es consciente de que "[...] hay una especie de transferencia entre el hombre y el mundo por medio del símbolo." (BEUCHOT, 2013, p. 148). Este traslado coincide con una absorción de la persona dentro del símbolo puesto que éste toma privilegio, igual que lo haría Dios en el caso de Panikkar o la obra de arte en Dilthey. De 
ahí que sea obvio que todas las dimensiones humanas sean coherentes entre sí (NISHIDA, 1995, p. 70), es decir, no se muestran incoherencias entre el pensar, el sentir o el hacer o, según Antón Pacheco, "[...] coinciden los modi essendi, los modi cognoscendi y los modi interpretandi." (ANTÓN PACHECO, 2010, p. 151). Esto no es debido a un voluntarismo forzado por el sujeto o la sociedad sino que parte de que el punto de origen de todas estas densidades se infiltra en cada una de ellas.

\subsection{Dejarse EXPERIMENTAR POR El SÍMbolo}

La desaparición del símbolo no es un fenómeno de índole física (los símbolos no han desaparecido) sino metafísica y epistemológica (la incapacidad para comprender los símbolos, mediante una actualización ontológica). Por ello, la restauración ha de darse en los mismos términos en que se abre el problema: no es preciso construir nuevas banderas sino actualizar la faz simbólica que están ocultas en las existentes, liberar su auténtica entraña oculta por hermenéuticas pragmatistas. María Zambrano lo explica admirablemente en Delirio y destino

Saber mirar un icono es liberar esa su esencia, traerla a nuestra vida, sin destruir la forma que la contiene, dejándola al mismo tiempo allí; es difícil y necesita entrenamiento [...]. Saber contemplar debe ser saber mirar con toda el alma, con toda la inteligencia y hasta con todo el cuerpo, lo cual es "participar", participar de la esencia contemplada en la imagen, hacerla vida. (ZAMBRANO, 1989, p. 160).

Zambrano aprendió a ver (recuperó la mirada ontológica) en dos contextos: en el Museo del Prado de Madrid y en sus paseos por el campo cuando una enfermedad la incapacitó para todo tipo de trabajo (ZAMBRANO, 1989, p. 152-153). El ejercicio era sencillo: mantener la visión constante en el cuadro o en el elemento con capacidad estética, como las nubes en un prado para acabar fusionándose con ellas o sentir que el individuo queda envuelto completamente por lo contemplado (PANIKKAR, 1999, p. 21); así se pasa de contemplador a ser contemplado. Antón Pacheco se acerca a este acto cuando señala como trayecto comprensivo la dinámica de "[...] cumplir y recorrer lo simbolizado mismo.” (ANTÓN PACHECO, 2010, p. 171). Por último, Dewey repite esta metodología criticando la visión del turista: 
Una multitud de visitantes llevados a través de una galería de arte por un guía, con la atención solicitada de un lado a otro, no perciben, sino que sólo por accidente se interesan en mirar un cuadro si es con intensidad. Para percibir, un contemplador debe crear su propia experiencia. Y esta creación debe incluir relaciones comparables a las que sintió el creador. (DEWEY, 2008, p. 62).

El apresurado turista ya no tiene una visión estética de Santa Sofía o de la catedral de Rouen, al igual que el automovilista a cien kilómetros por hora no ve el paisaje huidizo. Se debe caminar alrededor, dentro y fuera, y en visitas repetidas, dejar que la estructura se presente gradualmente bajo una iluminación variada y en conexión con estados de ánimo cambiantes. (DEWEY, 2008, p. 248).

Este modo contemplativo que conduce a la experiencia exhorta a la consecución de una serie de actitudes específicas que hemos explicado en trabajos previos (BARRIENTOS 2010; BARRIENTOS, 2011) y que aquí sólo citamos por razones de espacio: humildad, apertura, retiro asociativo, paciencia, fascinación por la novedad, equilibrio, escucha atenta del ritmo de la realidad y esperanza para que el misterio florezca o para que nosotros alcancemos la atalaya desde la que el misterio decida abrirse ante nosotros.

\subsection{LA COMPRENSIÓN DEL SÍMBOLO DESDE LA FUSIÓN DE HORIZONTES Y DESDE LA RESONANCIA DE ECOS COMUNES}

Gadamer (1977, p. 223) nos recuerda que la comprensión insta a “[...] dejar valer en mí algo contra mí." Sin embargo, esta idea se asienta en una visión que sigue incardinada en la subjetividad o la intersubjetividad. Por ello, se corre el riesgo de mantenernos en la limitación espacio-temporal aludida más arriba. Pero, ¿no sería posible abrirnos a una hermenéutica del símbolo consistente en la puesta en contacto de dos totalidades, esto es, asumir al yo como una trascendencia? Los juegos posthumanistas de las últimas décadas y ciertas tradiciones precartesianas nos animan a imaginar caminos de este calibre.

Por un lado, tenemos la teoría de la fusión de horizontes de Gadamer. El teórico alemán rompe los esquemas tradicionales de la comprensión (dos sujetos intercambiando información) por dos horizontes que se interpenetran y donde el sujeto juega un papel reducido (instrumento vacío que contempla la fusión que él mismo provocó. Repitámoslo: el diálogo se convierte en la 
fusión de los horizontes de dos sujetos o grupos antes que en la conversación concreta de estos.

La progresiva deshabituación de entender al sujeto bajo las categorías cartesianas o hegelianas, a saber, un ente con contornos definidos que siente como autónomos, propios e independientes del resto, introduce en una visión nueva y retadora de la persona y de sus interrelaciones: el sujeto y los grupos acaban conceptuándose como una síntesis orgánica y dinámica de experiencias que conforma un horizonte particular. Así, la conexión de una persona o sociedad con otra fragua un acontecimiento metafísico donde los horizontes (experienciales) de ambas entran en diálogo. La comunicación resulta de la fusión de horizontes de las dos entidades y de la vivificación de cada horizonte en el citado acontecimiento.

Trasladado al campo del símbolo, la comprensión exige la apertura del "propio" horizonte particular al horizonte vívido del símbolo y no la imposición de la propia subjetividad al símbolo; el segundo caso clausura la apertura del símbolo desde sí mismo. Ahora bien, ¿existe algún esquema que ayude a entender el contacto de ambos? Citamos más arriba a Huainanzi y su teoría de las resonancias. De acuerdo con esta teoría, uno comprende al otro o a lo otro cuando hace resonar en él un eco previamente instalado en su interior aunque no activo. Cuando interpretamos la nota musical "La" en una guitarra, resonará la cuerda de la nota "La" de la guitarra que se encuentra a su lado. El modelo hermenéutico respondería al mismo esquema: escuchar la transcendencia es una forma de hacer eco en la transcendencia que se encuentra en nuestro interior. Esta concepción parte de una imagen del ser humano como microcosmos donde nuestro ser no se concibe como un ente limitado espacio-temporalmente sino como potencialidad para una universalidad que duerme hasta que es activada de modo indirecto. El acto de comprensión simbólica partiría de los ecos que el símbolo provoca en nuestro horizonte. La primera voz que lanzamos en la montańa nos pertenece, la que regresa pertenece a la montańa y, sin embargo, algo las unifica. La llamada del símbolo le pertenece, pero el eco que gesta en nuestro interior se encuentra más de nuestro lado, aunque algo los unifica.

La imagen del parágrafo anterior es crucial puesto que las consecuencias nos conectan con el comienzo de este capítulo. Recordemos que diversos autores habían avisado de los peligros psicológicos y metafísicos del extravío simbólico: la persona adolecía de psicopatías o se quejaba de limitaciones existenciales insoportables. El punto al que hemos llegado nos explican la 
razón de la dolencia: el ser humano posee vocación de actualización de sus trascendencias, dormidas en su interior hasta que son despertadas por ecos de trascendencia (los del símbolo). Sin ellos, se siente la nostalgia del Hiperion (HÖLDERLIN, 2001) o la insoportabilidad de la estrechez mundana. Este trabajo demuestra, pues, que no sólo es posible recuperar experiencialmente el símbolo, sino que la sociedad requiere su reconquista so pena de muerte por inanición existencial.

La comprensión de una sociedad sobre sus símbolos muestra su potencia no sólo para crear ciudadanos autónomos sino personas que dan cumplimiento a lo que son, seres simbólicos (CASSIRER, 1967). Además, esta hermenéutica es la llave para salir de los atolladeros de fronteras individualistas que la conminan a su desaparición o, cuanto menos, a cercar la aventura hacia su autenticidad.

RASTROJO, José Barrientos. Aesthetics and the mystic in the experiential recovery of the symbol. Tans/formlação, Marília, v. 40, n. 3, p. 175-196, Jul./Set., 2017.

\begin{abstract}
This paper begins by discussing the weakness or loss of the symbol in our contemporary society, and recounts how modernity has renounced it by means of the discourse of Enlightenment. On these bases, we analyze the roots for its recovery, locating the symbol between the sign and analogy. We conclude with a proposal that restores the symbol by means of experience. The latter will open up the aesthetic and mystic worlds.
\end{abstract}

Keywords: Symbol. Experience. Aesthetic. Mystic. Analogy.

\title{
REFERENCIAS
}

ANTÓN PACHECO, J.A. El ser y los simbolos. Madrid: Mandala, 2010.

BARRIENTOS RASTROJO, J. El rostro de la experiencia desde la marea orteguiana y zambraniana. Revista Endoxa, v. 25, p. 279-314, 2010.

. La fisiología del saber de la experiencia y los frutos de su posesión. Themata, v. 44, p. 79-96, 2011.

BEUCHOT PUENTE, M. Las caras del simbolo: el ícono y el ídolo. Madrid: Caparrós, 1999a.

Perfiles esenciales de la hermenéutica. México DF: UNAM, 1999b. 
Antropología filosófica: hacia un personalismo analógico-icónico. Madrid:

Fundación Enmanuel Mounier, 2004. . Hermenéutica analógica, símbolo, mito y filosofía. México DF: UNAM, 2007. . Metáforas de nuestra vida: antropología e interpretación. Huelva: Hergué, 2011. - Belleza y analogía. México DF: San Pablo, 2012a.

\section{$2012 \mathrm{~b}$.}

. Ordo analogiae: interpretación y construcción del mundo. MéxicoDF: UNAM,

. El arte y su simbolo. Santiago de Querétaro: Caligrama, 2013.

CASSIRER, E. Antropología filosófica: introducción a la filosofía de la cultura. México DF: Fondo de Cultura Económica, 1967.

1971.

. Filosofía de las formas simbólicas I. México DF: Fondo de Cultura Económica,

CHENG, A. Historia del pensamiento chino. Barcelona: Bellaterra, 2002.

COMTE, A. Curso de filosofía positiva: discurso sobre el espíritu positivo. Barcelona: Folio, 2003.

DEWEY, J. Arte como experiencia. Barcelona: Paidós, 2008.

DURAND, G. La imaginación simbólica. Buenos Aires: Amorrortu, 1968.

ELÍAS, N. Teoría del símbolo: un ensayo de antropología cultural. Barcelona: Península, 1994.

FREUD, S. El porvenir de una ilusión. In: Obras completas III. Madrid:

Biblioteca Nueva, 1981.

GADAMER, H. G. Verdad y método I. Salamanca: Sígueme, 1999.

HEIDEGGER, M. Caminos del bosque. Madrid: Alianza, 2001.

HÖLDERLIN, F. Hyperion. Donostia: Erein, 2001.

LIPOVETSKY, G. El crepúsculo del deber. Barcelona: Anagrama, 2002.

MANNHEIM, K. Ideología y utopia: introducción a la sociología del conocimiento.

Madrid: Fondo de cultura económica, 1997.

MARX, K. Crítica de la filosofía del derecho de Hegel. Buenos Aires: Ediciones del Signo, 2005.

NISHIDA, K. Indagación sobre el bien. Barcelona: Gedisa, 1995.

PANIKKAR, R. Iconos del misterio: la experiencia de Dios. Barcelona: Península, 1999.

RICOEUR, P. Finitud y culpabilidad. Madrid: Trotta, 2004. 
SCHELEIERMACHER, F. Los discursos sobre hermenéutica. Navarra: Anuario filosófico, 1999.

TODOROV, T. Teorías del símbolo. Caracas: Monte Ávila, 1977.

UBALDO, N. Atlante illustrato di Filosofía. Prato: Demetra, 1999.

ZAMBRANO, M. (inédito a). Manuscrito 214.

. (inédito b). Manuscrito 257.

. Delirio y destino: los veinte años de una española. Madrid: Mondadori, 1989. . El hombre y lo divino. Madrid: Fondo de Cultura Económica, 1993. . Filosofía y poesía. Madrid: Fondo de Cultura Económica, 2001.

_. De la aurora. Madrid: Tabla Rasa, 2004.

ZUBIRI, X. Sócrates y la sabiduría griega. Escorial, v. 2, p. 187-226, 1940.

Recebido em 16/06/2015

Aceito em 17/05/2016 